\title{
GDSS MULTI KRITERIA PENENTUAN STRATEGI MARKETING TERBAIK PERGURUAN TINGGI
}

\author{
Sumiyatun ${ }^{1}$, Luthfan Hadi Pramono ${ }^{2}$ \\ ${ }^{1)}$ Teknik Informatika STMIK AKAKOM ${ }^{2)}$ Teknik Komputer STMIK AKAKOM \\ JI Raya Janti No 143 Yogyakarta 55198 \\ Email: sumiyatun@akakom.ac.id ${ }^{1}$, luthfan@akakom.ac.id ${ }^{2}$
}

\begin{abstract}
Dunia pendidikan telah mengalami evolusi secara kontinyu. Salah satu faktor pemicunya adalah kompetisi antar perguruan tinggi yang semakin ketat. Oleh karena itu pemasaran menjadi unsur yang strategis dalam menjaga eksistensi perguruan tinggi. Dalam membuat keputusan pemilihan strategi marketing, terdapat beberapa kriteria yang perlu dipertimbangkan, diantaranya adalah biaya, waktu, tingkat pengaruh, capaian target dan lain sebagianya. Pada perguruan tinggi swasta pengambilan keputusan terkait strategi marketing tidak hanya ditentukan oleh bagian Humas saja, akan tetapi harus meminta pertimbangan dari pihak manajemen dan yayasan pemilik perguruan tinggi.
\end{abstract}

Berdasarkan kompleknya permasalahan yang dihadapi, diperlukan sebuah sistem pendukung keputusan kelompok atau Group Decision Support System (GDSS) dalam menentukan strategi marketing pergurauan tinggi. Pada penelitian ini, penulis mengajukan GDSS menggunakan metode Analytical Hierarchy Process (AHP) yang mendukung model Multi Attribute Decision Making (MADM) dan Technique for Order Preference by Similarity to Ideal Solution (TOPSIS) sebagai model untuk pengambilan keputusan.

Penggunaan GDSS pada penelitian ini bertujuan untuk mengakomodir penilaian lebih dari satu evaluator dan meningkatkan kualitas keputusan. Dengan demikian diharapkan penilaian yang dilakukan lebih obyektif, karena tidak dilakukan oleh satu pihak saja. Perangkat lunak yang dibangun dari hasil penelitian ini diharapkan mempermudah dan mempercepat dalam menentukan strategi marketing perguruan tinggi.

Keyword : AHP, GDSS, MADM, perguruan tinggi, strategi marketing, TOPSIS

\section{PENDAHULUAN}

Tidak semua perguruan tinggi memiliki Unit Marketing, biasanya ada perguruan tinggi hanya memiliki unit namanya HUMAS atau promosi. Unit tersebut menangani berbagai hal misalnya pemberitaan media, memberikan informasi kepada civitas akademika tentang kegiatan perguruan tinggi, serta lakukan promosi dengan media brosur, advertorial di media atau melakukan presentasi di tiap tiap sekolah SMA khususnya kelas III (Widiyoko, 2015). 
Proses mengambil sebuah keputusan selalu diupayakan secara objektif, cepat dan tepat. Untuk mendukung pengambil keputusan dalam menentukan keputusan saat ini telah banyak melibatkan sistem pendukung keputusan. Dalam membangun sistem pendukung keputusan tentunya melibatkan berbagai metode sistem pendukung keputusan, berbagai metode telah diterapkan pada sistem pendukung keputusan untuk menghasilkan alternatif yang sesuai dengan kriteria-kriteria yang telah ditetapkan oleh suatu organisasi atau perusahaan. Berbagai metode yang telah diterapkan tentunya terdapat kelebihan dan kelemahan yang banyak dipaparkan di setiap kajian, penyempurnaan tentunya selalu dilakukan dari berbagai penelitian. (Chamid dan Murti, 2017).

Dalam membuat keputusan pemilihan strategi marketing, terdapat beberapa kriteria yang perlu dipertimbangkan, diantaranya adalah biaya, waktu, tingkat pengaruh, capaian target dan lain sebagianya. Pada perguruan tinggi swasta pengambilan keputusan terkait strategi marketing tidak hanya ditentukan oleh bagian Humas saja, akan tetapi harus meminta pertimbangan dari pihak manajemen dan yayasan pemilik perguruan tinggi. Tidak jarang antara pihak pegambil keputusan tersebut mengalami kesulitan, bahkan memerlukan diskusi yang sangat panjang dalam menentukan strategi marketing dari perguruan tinggi tersebut. Hal ini disebabkan karena dari setiap pengambil keputusan memiliki penilaian tersendiri terkait dengan kriteria - kriteria yang digunakan dalam mengambil keputusan.

Berdasarkan permasalahan yang dihadapi, diperlukan sebuah sistem pendukung keputusan kelompok atau Group Decision Support System (GDSS) dalam menentukan strategi marketing pergurauan tinggi. Pada penelitian ini, penulis mengajukan GDSS menggunakan metode Analytical Hierarchy Process (AHP) yang mendukung model Multi Attribute Decision Making (MADM) dan Technique for Order Preference by Similarity to Ideal Solution (TOPSIS) sebagai model untuk pengambilan keputusan.

GDSS digunakan untuk mengakomodir preferensi dari para pengambil keputusan. Hal ini didasari bahwa pengambilan keputusan strategi marketing perguruan tinggi swasta melibatkan humas, manajemen dan yayasan. Beberapa keuntungan dari 
GDSS, diantaranya dapat mendukung aktivitas kelompok, memberikan kecepatan hasil akhir keputusan yang akan diperoleh, masing-masing pengambil keputusan (evaluator) dapat mengambil keputusan secara online dari manapun, dan dapat dilakukan secara bersama-sama pada saat yang bersamaan atau tidak bersamaan. Penggunaan GDSS pada penelitian ini bertujuan untuk mengakomodir penilaian lebih dari satu evaluator dan meningkatkan kualitas keputusan. Dengan demikian diharapkan penilaian yang dilakukan lebih obyektif, karena tidak dilakukan oleh satu pihak saja.

Metode AHP digunakan didasarkan pada pendapat bahwa metode AHP merupakan salah satu metode Multi Criteria Decision Making (MCDM) yang sangat baik dalam memodelkan pendapat para ahli dalam sistem pendukung keputusan (Muhardono \& Isnanto 2014).

Kombinasi metode AHP dan TOPSIS dipilih dengan alasan metode AHP memliki kelebihan berdasar pada matriks perbandingan pasangan dan melakukan analisis konsistensi. Sedangkan metode TOPSIS dapat menyelesaikan pengambilan keputusan secara praktis, karena konsepnya sederhana dan mudah dipahami, komputasinya efisien, serta memiliki kemampuan mengukur kinerja relatif dari alternatif-alternatif keputusan (Juliyanti dkk 2011).

Oleh karena itu dalam penelitian ini akan dikembangankan sebuah sistem pendukung keputusan kelompok untuk menentukan strategi marketing terbaik sekolah tinggi menggunakan metode AHP dan TOPSIS dengan studi kasus pada STMIK AKAKOM Yogyakarta.

\section{METODE}

Dalam penelitian ini menerapkan 2 metode, yaitu AHP dan TOPSIS. AHP digunakan untuk menentukan bobot dan TOPSIS digunakan untuk melakukan perangkingan.

1. Metode Analytical Hierarchy Process (AHP)

Setelah matriks perbandingan berpasangan dibuat, maka langkah selanjutnya adalah menghitung bobot kriteria.

Mengalikan nilai dari masing - masing baris dan menghitung akar pangkat $\mathrm{n}$.

$$
\bar{W}_{i}=\sqrt[n]{\prod_{j=1}^{n} a_{i j}}
$$


$\overline{\boldsymbol{W}}_{\boldsymbol{i}} \quad$ : bobot kriteria ke $-i$ yang belum dinormalisasi

$a_{i j} \quad$ : penilaian kepentingan kriteria ke $i$ dibandingkan dengan kriteria $\mathrm{ke}-j$

$i \quad: 1$...n merupakan jumlah kriteria

Melakukan normalisasi terhadap akar pangkat untuk mendapatkan bobot (eigen vector) yang sesuai.

$$
W_{i}=\frac{\bar{W}_{i}}{\sum_{i=1}^{n} \bar{W}_{i}}
$$

$\boldsymbol{W}_{\boldsymbol{i}}$ : bobot kriteria ke $-i$ yang sudah dinormalisasi

a. Mengukur konsistensi

1. Menghitung nilai eigen value $(\lambda \max )$ dengan Persamaan (3.4):

$$
=\sum_{j=1}^{\lambda_{\max }} \sum_{i=1}^{n} a_{i j} W_{i}
$$

Keterangan:

$\lambda \max$ : Nilai eigen value maksimum

Nilai eigen value didapatkan dengan menjumlahkan nilai yang terdapat pada matriks perbandingan berpasangan berdasarkan kolom kriteria, dan jumlahnya dikalikan dengan masing masing bobot yang sudah ternormalisasi.
2. Menghitung indeks konsistensi (consistency index) dengan Persamaan :

$$
\boldsymbol{C I}=\left(\lambda_{\max }-\boldsymbol{n}\right) /(\boldsymbol{n}-
$$

\section{1)}

Keterangan:

CI : Consistency Index

$\lambda_{\max }$ : eigen value

$\boldsymbol{n}$ : Banyaknya elemen

3. Menghitung rasio konsistensi (consistency ratio) dengan Persamaan

$$
C R=C I / R I
$$

Keterangan:

$C I$ : Consistency Index ; CR :

Consistency Ratio; RI: Random Index

Adapun Random Index yang digunakan dapat dilihat pada Tabel 1

Tabel 1 Nilai Random Index

\begin{tabular}{|l|c|c|c|c|c|c|}
\hline $\begin{array}{l}\text { Ukuran } \\
\text { Matriks }\end{array}$ & 2 & 3 & 4 & 5 & 6 & 7 \\
\hline $\begin{array}{l}\text { Random } \\
\text { Index }\end{array}$ & $\begin{array}{l}0,0 \\
0\end{array}$ & 0,53 & 0,90 & 1,12 & 1,24 & 1,32 \\
\hline
\end{tabular}

2. Metode TOPSISrosedur dari metode TOPSIS yang digunakan mengikuti langkah-langkah sebagai berikut:

1. Menentukan matriks keputusan yang ternormalisasi. 


$$
r_{i j}=\frac{x_{i j}}{\sqrt{\sum_{i=1}^{m} x_{i j}^{2}}}
$$

Keterangan:

$\boldsymbol{r}_{\boldsymbol{i} \boldsymbol{j}} \quad$ : nilai data ternormalisasi berdasarkan tiap alternatif $\mathrm{ke}-i$ dari setiap kriteria $\mathrm{ke}-j$

$\boldsymbol{x}_{\boldsymbol{i} \boldsymbol{j}}$ : nilai data belum ternormalisasi berdasarkan tiap alternatif $\mathrm{ke}-i$ dari setiap kriteria ke $-j$

R : Matriks keputusan ternormalisasi

i $: 1,2, \ldots \mathrm{m}$ merupakan jumlah alternatif (baris)

j $\quad: 1,2, \ldots n$ merupakan jumlah kriteria (kolom)

Berdasarkan persamaan akan diperoleh matriks ternormalisasi (R) yaitu

$$
R=\left[\begin{array}{cccc}
\frac{r_{11}}{r_{21}} & \frac{r_{12}}{r_{22}} & \cdots & \frac{r_{1 n}}{r_{2 n}} \\
\vdots & \vdots & \ddots & \vdots \\
r_{m 1} & r_{m 2} & \cdots & r_{m n}
\end{array}\right]
$$

2. Menghitung solusi ideal positif dan solusi ideal negatif.

Penentuan solusi ideal positif $\left(S_{j}^{+}\right)$ dan solusi ideal negatif $\left(S_{j}^{-}\right)$dipengaruhi oleh sifat kriteria apakah benefit atau cost. Kritetia yang bersifat benefit adalah kriteria yang apabila penilaiannya semakin tinggi maka semakin bagus.

$$
\begin{aligned}
& S_{j}^{+}=\left\{\boldsymbol{r}_{1}^{+}, \ldots, \boldsymbol{r}_{n}^{+}\right\} \\
& =\left\{\begin{array}{c}
\operatorname{maks}_{\boldsymbol{i}} \boldsymbol{r}_{i j}, \boldsymbol{j} \epsilon B \\
\min _{\boldsymbol{i}} \boldsymbol{r}_{\boldsymbol{i j}}, \boldsymbol{j} \epsilon C
\end{array}\right.
\end{aligned}
$$

$$
\begin{aligned}
& S_{j}^{-}=\left\{r_{1}^{-}, \ldots, r_{n}^{-}\right\} \\
& =\left\{\begin{array}{c}
\operatorname{maks}_{i} \boldsymbol{r}_{i j}, j \epsilon C \\
\min _{\boldsymbol{i}} \boldsymbol{r}_{\boldsymbol{i j}}, j \epsilon B
\end{array}\right.
\end{aligned}
$$

\section{Keterangan:}

$\boldsymbol{r}_{j}^{+} \quad$ : solusi ideal positif berdasarkan kriteria ke $-j$

$\boldsymbol{r}_{\boldsymbol{j}}^{-} \quad$ : solusi ideal negatif berdasarkan kriteria ke $-j$

$j \quad: \quad 1,2, \ldots \mathrm{n}$ merupakan jumlah kriteria

$S_{j}^{+} \quad$ : solusi ideal positif terhadap kriteria ke $-j$

$S_{j}^{-} \quad$ : solusi ideal negatif terhadap kriteria ke $-j$

$B \quad$ : himpunan kriteria yang bersifat benefit

C : himpunan kriteria yang bersifat cost

3. Menghitung jarak antara nilai setiap alternatif dengan matriks solusi ideal positif dan matriks solusi ideal negatif.

$$
\begin{aligned}
& D_{i}^{+}=\sqrt{\sum_{j=1}^{n} W c_{j}\left(r_{i j}-r_{j}^{+}\right)^{2}} \\
& D_{i}^{-}=\sqrt{\sum_{j=1}^{n} W c_{j}\left(r_{i j}-r_{j}^{-}\right)^{2}}
\end{aligned}
$$


Keterangan:

$i \quad: 1,2, \ldots$ m merupakan jumlah alternatif

$j \quad: 1,2, \ldots$ n merupakan jumlah kriteria

$\boldsymbol{D}_{\boldsymbol{i}}^{+}$: jarak setiap alternatif dari solusi ideal positif $\left(S_{j}^{+}\right)$

$\boldsymbol{D}_{\boldsymbol{i}}^{-}$: jarak setiap alternatif dari solusi ideal negatif $\left(S_{j}^{-}\right)$

$\boldsymbol{W} \boldsymbol{c}_{\boldsymbol{j}}$ : nilai bobot kriteria $\mathrm{ke}-j$ yang didapatkan dari pembobotan AHP

$\boldsymbol{r}_{\boldsymbol{i} j}$ : nilai data ternormalisasi

berdasarkan tiap alternatif $\mathrm{ke}-i$ dari setiap kriteria ke $-j$

$\boldsymbol{r}_{j}^{+}$: solusi ideal positif berdasarkan kriteria ke $-j$

$\boldsymbol{r}_{\boldsymbol{j}}^{-}$: solusi ideal negatif berdasarkan kriteria ke $-j$

4. Menghitung nilai closeness coefficient untuk setiap alternatif.

Tahap akhir dari TOPSIS adalah mencari nilai closeness coefficient yang merupakan nilai preferensi untuk setiap alternatif

$$
C C_{i}=\frac{D_{i}^{-}}{D_{i}^{-}+D_{i}^{+}}
$$

Keterangan:

i : $1,2, \ldots$ m merupakan jumlah alternatif media promosi

$C C \mathrm{i} \quad$ : kedekatan tiap alternatif $\mathrm{ke}-\mathrm{i}$ terhadap solusi ideal

$\boldsymbol{D}_{\boldsymbol{i}}^{+}$: jarak alternatif $k e-i$ dengan solusi ideal positif

$\boldsymbol{D}_{\boldsymbol{i}}^{-}$: jarak alternatif $k e-i$ dengan solusi ideal negative
Selanjutnya nilai dari closeness coeffisient digunakan menentukan perangkingan dari alternatif, dimana alternatif dengan nilai $C C$ terbesar merupakan solusi yang dipilih.

\section{HASIL DAN PEMBAHASAN}

Dalam penelitian ini terdapat 3 kelompok yang yang akan melakukan pengambilan keputusan yaitu bagian Humas dan Admisi, Manajemen dan Yayasan. Adapun gambaran model pemilihan strategi marketing ditunjukkan pada Gambar 2.

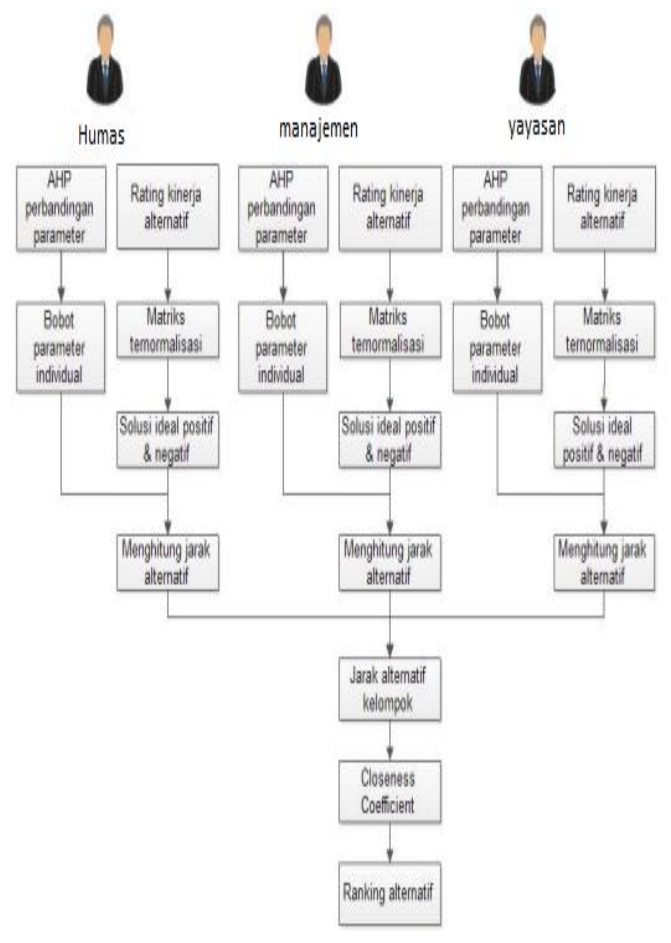

Gambar 2. Gambaran model pemilihan strategi marketing 
Penilaian alternatif dilakukan

oleh masing-masing evaluator berdasarkan parameter subyektif didasarkan pada penilaian atau persepsi masing-masing evaluator terhadap alternatif. Selanjutnya dilakukan perangkingan alternatif menggunakan metode TOPSIS. Agregasi penilaian individual menjadi penilaian kelompok dilakukan pada proses perhitungan jarak alternatif ke solusi ideal positif dan solusi ideal negatif kelompok menggunakan geometric mean.

Parameter yang digunakan sebagai kriteria dalam Sistem Pendukung Keputusan kelompok ini seperti pada tabel 2.

Tabel 2. Kriteria

\begin{tabular}{|l|l|l|}
\hline \multicolumn{1}{|c|}{ No } & \multicolumn{1}{|c|}{ Kode } & \multicolumn{1}{|c|}{ Kriteria } \\
\hline 1 & C1-CT & Capaian target \\
\hline 2 & C2-TP & Tingkat pengaruh \\
\hline 3 & C3-BI & Biaya \\
\hline 4 & C4-JK & Jangkauan \\
\hline 5 & C5-KI & $\begin{array}{l}\text { Kelengkapan } \\
\text { Informasi }\end{array}$ \\
\hline
\end{tabular}

Adapun alternatif yang digunakan sebagai strategi marketing adalah seperti pada tabel 3
Tabel 3. Alternatif

\begin{tabular}{|l|l|l|}
\hline \multicolumn{1}{|c|}{ No } & \multicolumn{1}{|c|}{ Kode } & \multicolumn{1}{c|}{ Strategi } \\
\hline 1 & A1 & Promosi di media \\
\hline 2 & A2 & $\begin{array}{l}\text { Pemberian } \\
\text { Beasiswa }\end{array}$ \\
\hline 3 & A3 & $\begin{array}{l}\text { Pameran } \\
\text { Pendidikan }\end{array}$ \\
\hline 4 & A4 & kerjasama \\
\hline 5 & A5 & Internet \\
\hline
\end{tabular}

Berdasarkan hasil perhitungan AHP diperoleh bobot masing-masing parameter dari ketiga evaluator, yaitu berupa nilai eigen vector seperti terlihat pada tabel 4.

Tabel 4. Bobot Kriteria

\begin{tabular}{|c|c|c|c|}
\hline \multirow[b]{2}{*}{$\begin{array}{l}\text { Kriteri } \\
\text { a }\end{array}$} & \multicolumn{3}{|c|}{ Bobot kriteria } \\
\hline & $\begin{array}{l}\text { Humas } \\
\text { dan } \\
\text { Admis } \\
\text { i }\end{array}$ & $\begin{array}{c}\text { Manajeme } \\
n\end{array}$ & $\begin{array}{c}\text { Yayasa } \\
\mathrm{n}\end{array}$ \\
\hline $\mathrm{C} 1-\mathrm{CT}$ & 0,3014 & 0,2831 & 0,2617 \\
\hline C2-TP & 0,1596 & 0,1351 & 0,1727 \\
\hline C3-BI & 0,1834 & 0,2096 & 0,2279 \\
\hline C4-JK & 0,0877 & 0,0891 & 0,0760 \\
\hline $\mathrm{C} 5-\mathrm{KI}$ & 0,2680 & 0,2831 & 0,2617 \\
\hline
\end{tabular}


Tabel 5 Penilaian alternatif

\begin{tabular}{|c|c|c|c|c|c|c|}
\hline \multirow{2}{*}{$\begin{array}{l}\text { Kriter } \\
\text { ia }\end{array}$} & \multirow[t]{2}{*}{ Evaluator } & \multicolumn{5}{|c|}{ Alternatif } \\
\hline & & A & $\begin{array}{c}\mathrm{A} \\
2\end{array}$ & $\begin{array}{c}\mathrm{A} \\
3\end{array}$ & $\begin{array}{l}\mathrm{A} \\
4\end{array}$ & $\begin{array}{c}\mathrm{A} \\
5\end{array}$ \\
\hline \multirow[t]{3}{*}{$\begin{array}{l}\mathrm{C} 1- \\
\mathrm{CT}\end{array}$} & $\begin{array}{l}\text { Humas } \\
\text { dan } \\
\text { Admisi }\end{array}$ & 3 & 1 & 4 & 5 & 3 \\
\hline & $\begin{array}{l}\text { Manajem } \\
\text { en }\end{array}$ & 4 & 2 & 3 & 4 & 2 \\
\hline & Yayasan & 3 & 1 & 4 & 4 & 3 \\
\hline \multirow[t]{3}{*}{$\begin{array}{l}\text { C2- } \\
\text { TP }\end{array}$} & $\begin{array}{l}\text { Humas } \\
\text { dan } \\
\text { Admisi }\end{array}$ & 3 & 4 & 3 & 3 & 4 \\
\hline & $\begin{array}{l}\text { Manajem } \\
\text { en }\end{array}$ & 4 & 3 & 2 & 4 & 3 \\
\hline & Yayasan & 2 & 3 & 3 & 5 & 5 \\
\hline \multirow[t]{3}{*}{ C3-BI } & $\begin{array}{l}\text { Humas } \\
\text { dan } \\
\text { Admisi }\end{array}$ & 3 & 3 & 2 & 1 & 1 \\
\hline & $\begin{array}{l}\text { Manajem } \\
\text { en }\end{array}$ & 2 & 3 & 4 & 1 & 1 \\
\hline & Yayasan & 3 & 4 & 3 & 1 & 1 \\
\hline \multirow[t]{3}{*}{ C4-JK } & $\begin{array}{l}\text { Humas } \\
\text { dan } \\
\text { Admisi }\end{array}$ & 4 & 2 & 3 & 4 & 5 \\
\hline & $\begin{array}{l}\text { Manajem } \\
\text { en }\end{array}$ & 3 & 3 & 4 & 3 & 5 \\
\hline & Yayasan & 2 & 4 & 3 & 3 & 5 \\
\hline \multirow[t]{3}{*}{ C5-KI } & $\begin{array}{l}\text { Humas } \\
\text { dan } \\
\text { Admisi }\end{array}$ & 4 & 3 & 2 & 3 & 4 \\
\hline & $\begin{array}{l}\text { Manajem } \\
\text { en }\end{array}$ & 2 & 3 & 2 & 4 & 3 \\
\hline & Yayasan & 4 & 4 & 3 & 3 & 5 \\
\hline
\end{tabular}

Dengan megunakan meode topsis yang sudah dimodifikasi diperoleh urutan ranking dari media yang sudah digunakan.

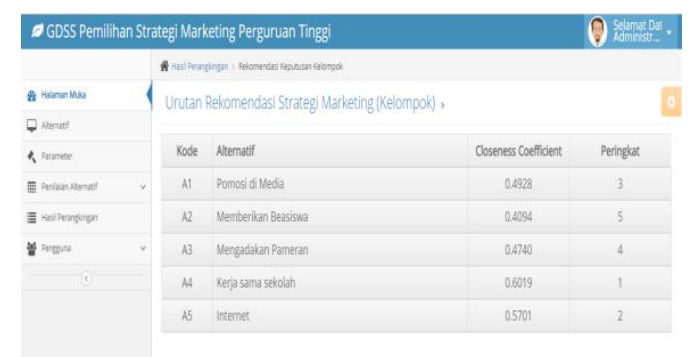

Gambar 3 Urutan rekomendasi

Berdasarkan hasil diperoleh urutan strategi marketing sesuai dengan kriteria yang digunakan, dimana alternatif yang memiliki nilai closeness coefficient paling besar merupakan prioritas teratas. Urutan alternatif strategi mrketing yang diperoleh berturut - turut dari peringkat pertama adalah : A4 (kerjasama sekolah) dengan nilai 0,6019, A5 (internet) dengan nilai 0,5701, A1 (promosi di media) dengan nilai 0,4928, A3 (mengadakan pameran) dengan nilai 0,4740 dan A2 (pemberian beasiswa) dengan nilai 0,4094

\section{KESIMPULAN DAN SARAN}

\section{Kesimpulan}

Dari uraian keseluruhan yang telah dikemukakan dapat disimpulkan bahwa pengambilan keputusan dapat dilakukan secara kelompok, sehingga 
hasil yang diproleh lebih objektif dan aplikasi yang telah dibangun dapat dimanfaatkan pihak terkait dalam mengambil kesimpulan.

\section{Saran}

Dapat dilakukan penelitian kembali dengan metode yang lainnya kemudian hasilnya dapat dibandingkan dengan penelitian yang sudah dikerjaka ini.

\section{DAFTAR PUSTAKA}

Chamid A. A., \& Murti A.C., 2017, Kombinasi Metode AHP dan Topsis pada Sistem Pendukung Keputusan, SNATIF, Kudus

Juliyanti, Irawan, M.I. \& Mukhlash, I., 2011. Pemilihan Guru Berprestasi Menggunakan Metode Ahp Dan Topsis. In Prosiding Seminar Nasional Penelitian, Pendidikan dan Penerapan MIPA, Fakultas MIPA, Universitas Negeri Yogyakarta. pp. 63-68.

Muhardono, A. \& Isnanto, R.R., 2014. Penerapan Metode AHP dan Fuzzy Topsis Untuk Sistem Pendukung Keputusan Promosi
Jabatan. Jurnal Sistem Informasi Bisnis, 2, pp.108-115.

Widiyoko, S., 2015, Strategi Marketing Perguruan Tinggi, http://www.kompasiana.com/se tiawan_wd/strategi-marketing Perguruantinggi_550e68b2a33 311a32dba8275, diakses pada tanggal 8 Oktober 2016 